\title{
Palladium Nanoparticles Supported on Highly Oriented Pyrolytic Graphite: Preparation, Reactivity and Stability
}

\author{
Wenbo Ju, ${ }^{[a, b]}$ Tine Brülle, ${ }^{[a]}$ Marco Favaro, ${ }^{[c]}$ Lorenzo Perini, ${ }^{[c]}$ Christian Durante, ${ }^{[c]}$ \\ Oliver Schneider, ${ }^{*[a, b]}$ and Ulrich Stimming ${ }^{[a, d]}$
}

\begin{abstract}
Palladium nanoparticles (Pd NPs) were deposited electrochemically on highly oriented pyrolytic graphite (HOPG) substrates by using a potentiostatic double-pulse technique. The particle densities were in the order of $10^{9} \mathrm{~cm}^{-2}$; the radius of the deposited Pd NPs $(2-20 \mathrm{~nm})$ was proportional to the $1 / 3$ power of the growth pulse duration $\left(t_{g}{ }^{1 / 3}\right)$. The open-circuit potential measured during potentiodynamic potential scans of hydrogen evolution/oxidation (HER/HOR) at Pd/HOPG electrodes (average radii of Pd NPs larger than $8 \mathrm{~nm}$ ) was more negative than at a bulk Pd electrode; this was caused by the different phases of palladium hydride $\left(\mathrm{PdH}_{x}\right)$ formed in the latter case. $\mathrm{Pd}$ / HOPG samples showed an increased specific current density
\end{abstract}

with decreasing particle size in HER. The activity of Pd NPs for HER is primarily affected by the absorbed-hydrogen-atom content in the Pd lattice. The electrochemical activity of Pd NPs for the oxygen reduction reaction (ORR) in acidic media decreased for smaller particle sizes. The stability of the Pd NPs was significantly influenced by the $\mathrm{pH}$ of the electrolyte. $\mathrm{Pd}$ NPs had a higher dissolution rate in solution with lower $\mathrm{pH}$. The degeneration mechanisms seen for Pd NPs on HOPG were the dissolution of metal atoms, detachment of particles, and particle agglomeration. Corrosion of the graphite substrate after the potential cycles was also observed in AFM images.

\section{Introduction}

The overall performance of the polymer electrolyte membrane fuel cell (PEMFC) essentially depends on the catalytic activity of its core part: the membrane electrode assembly (MEA). Platinum-based catalysts, which are frequently used in PEMFCs, contribute significantly to the total stack cost due to its high price. ${ }^{[1]}$ Replacing or reducing the amount of Pt-based catalysts, particularly in the cathode catalyst layer, without compromising the systematic performance is a promising strategy with which to meet the cost requirement for commercialisation of the fuel cell. Pd is a potential substitute for Pt, because it has more abundant reserves and costs less than Pt. As for Pt, $\mathrm{Pd}$ is stable under extremely corrosive conditions, although not at potentials above $0.9 \mathrm{~V}$. Although the electrocatalytic activities of pure $\mathrm{Pd}$ for the hydrogen oxidation/evolution reaction (HOR/HER) and the oxygen reduction reaction (ORR) are at least five times lower than that of $\mathrm{Pt}^{[2 \mathrm{a}, \mathrm{b}]}$ the price advantage of $\mathrm{Pd}$ (roughly half price of $\mathrm{Pt}$ ) continues to drive research ef-

[a] W. Ju, Dr. T. Brülle, Dr. O. Schneider, Prof. U. Stimming

Physik-Department E19, Technische Universität München

James-Franck-Str.1, 85748, Garching b. München (Germany)

E-mail:oliver_m.schneider@tum.de

[b] W. Ju, Dr. O. Schneider

Institut für Informatik VI, Technische Universität München

Schleißheimer Str. 90a, 85748, Garching b. München (Germany)

[c] M. Favaro, L. Perini, Dr. C. Durante

Dipartimento di Scienze Chimiche, Università degli Studi di Padova

Via Marzolo 1, 35131, Padova, (Italy)

[d] Prof. U. Stimming

School of Chemistry, Faculty of Science

Agriculture and Engineering, Newcastle University

Newcastle upon Tyne NE1 TRU (United Kingdom) forts aimed at improving the activity of Pd by surface modification and alloying.

Catalysts at both fuel cell electrodes are commonly prepared in the form of nanometer-sized particles for the purpose of sustaining high levels of metal dispersion. Compared with bulk materials, the corresponding nanostructured metal particles show significantly different properties. For instance, bulk gold is well-known to be inert towards many reactions, whereas nanometre-sized Au particles show excellent electrocatalytic activities, such as in the ORR and in the carbon monoxide oxidation reaction. ${ }^{[3 a-c]}$ Furthermore, some reactions catalysed by metal nanoparticles (NPs) show a strong particle-size sensitivity. Antoine et al. ${ }^{[4]}$ reported that the activity of Pt NPs for the HOR was improved when the particle size decreased, and Brülle et al. ${ }^{[3]}$ and El-Deab et al..$^{[5]}$ found that the electrocatalytic activity of Au NPs for ORR increased when the particle size was reduced; this was attributed to the elevated proportion of low coordinated atoms (or edge sites), which can alter the adsorption enthalpy of reactants (or products) and thereby enhance the reaction rate at smaller particle size. ${ }^{[6]}$ Another explanation is a change in the morphology, especially in the facets preferentially exposed at different particle sizes. ${ }^{[7 a-c]}$

$\mathrm{Pd}$ affords a more complex picture than Pt because of its strong hydrogen absorption behaviour and because of the dependence of its properties on the hydrogen content. ${ }^{[8, b, c, d]}$ Considerable efforts have been dedicated towards investigating the electrochemical properties of supported Pd. Markovic et al. ${ }^{[9]}$ demonstrated that the activity of a $\mathrm{Pd}$ monolayer on $\mathrm{Pt}(111)$ for HER/HOR is even higher than that of a pure $\mathrm{Pt}(111)$ surface. Shao et al. ${ }^{[10]}$ compared the reaction rates of oxygen 
reduction on $\mathrm{Pd}(111)$ and $\mathrm{Pd}$ monolayers on several substrates and found that the activity for ORR increases in the order $\mathrm{Pd} / \mathrm{Ru}(0001)<\mathrm{Pd} / \mathrm{Ir}(111)<\mathrm{Pd} / \mathrm{Rh}(111)<\mathrm{Pd} / \mathrm{Au}(111)<\mathrm{Pd}(111)$ $<\mathrm{Pd} / \mathrm{Pt}$ (111). Pandelov and Stimming ${ }^{[11]}$ observed that the activity of a Pd sub-monolayer on $\mathrm{Au}(111)$ for HER strongly depends on the coverage. A similar effect was observed for the HOR. ${ }^{[12]}$

Electrochemical properties of supported Pd NPs can be influenced by many factors, such as support effects, strain effect, particle-size effects, dispersion, the proportion of low coordinated atoms (edge atoms, kinks and other defects) and others. Many authors ${ }^{[9,10]}$ ascribed the altered electrochemical behaviour of a Pd ad-layer on support materials with various lattice constants to the changes in the electronic structure due to lateral strain, which leads, according to the Nørskov model, ${ }^{[13]}$ to a shift of the d-band centre. Additionally, the direct electronic interaction between substrate material and ad-layer contributes to the changed electrochemical behaviour ("ligand effect" ${ }^{\prime 1}{ }^{[1]}$ With increasing Pd coverage, a gradual change of the properties of the Pd ad-layers to bulk properties was observed due to the gradually weakened support effect. ${ }^{[15]}$ Kibler et al. ${ }^{[16 a-c]}$ investigated $\mathrm{Pd}$ ad-layers on $\mathrm{Au}(111), \mathrm{Au}(110)$, and $\mathrm{Au}(100)$, and concluded that the change of electrochemical properties was caused not only by the strain effects, but also by the formation of a Pd-Au alloy on $\mathrm{Au}(110)$ and $\mathrm{Au}(100)$ surfaces. Björketun's theoretical work indicated that different adsorption sites at $\mathrm{Pd}$ nanoclusters supported on $\mathrm{Au}(111)$ had a different free energy of adsorption for the hydrogen atom, and that the edges of the Pd islands were the optimal adsorption sites for hydrogen atoms. ${ }^{[17]}$ This conclusion was also confirmed theoretically by Quanio et al. ${ }^{[18]}$ Stimming et al. ${ }^{[1]}$ proposed the "spillover" effect of adsorbed hydrogen from $\mathrm{Pd}$ nano-islands to the Au surface as an explanation for the enhanced electrocatalytic activity. In this interpretation, the distance between $\mathrm{Pd}$ nano-islands plays an important role in the reaction rate.

Previous investigations indicate that the catalytic properties of Pd NPs are size-dependent. However, the geometric and electronic properties are always affected by the combination of particle-size effects and particle-support interaction. To gain a further understanding of the size-related effects, support-related factors should be eliminated, or at least significantly weakened. Highly oriented pyrolytic graphite (HOPG) possesses chemical inertia. Its weak binding to noble metal particles excludes support-related effects from a particle-support system. ${ }^{[3,19]}$ Factors that could influence the electrocatalytic activities of Pd NPs on HOPG are the ratio of low-coordinated atoms, structural parameters (shape effects), particle dispersion, and particle composition (hydrogen content). The use of a carbon support also affects the electrochemical deposition and the particle shape: in particular, a change from epitaxial layer-by-layer growth to three-dimensional growth is observed. With respect to potential fuel cell applications, this system represents a more realistic model system.

The preparation of Pd NPs with narrow size- and particle density-distribution is as crucial as the controlled variation of particle size in the study of size-dependent properties. The po- tentiostatic double-pulse deposition technique (one short-time high-overpotential nucleation pulse followed by a long-time, low-overpotential growth pulse), which is widely applied in many groups, ${ }^{[3,20 a-d]}$ has distinct advantages compared with other techniques, such as high efficiency, convenience, and reproducibility. The separation of nucleation and growth makes it possible to control the particle density and size independently by varying the parameters of the two pulses.

In this work, the potentiostatic double-pulse deposition technique was used to prepare Pd NPs with a range of radii on HOPG. The morphology of the resulting nanostructured surfaces was investigated by tapping-mode atomic force microscopy (TM-AFM). The catalytic activities for HER and ORR were measured by using linear-sweep voltammetry in acidic electrolyte. The stability of the Pd NPs on HOPG was also studied in acidic electrolytes with a range of $\mathrm{pH}$ values.

\section{Results}

\subsection{Electrodeposition of Pd NPs}

Pd NPs were deposited electrochemically by the potentiostatic double-pulse method. While the nucleation potential of $-70 \mathrm{mV}$ vs. RHE (all potentials in this paper are converted to the RHE scale, if not explicitly stated otherwise) is applied to the HOPG electrode for $10 \mathrm{~ms}$ (Figure $1 \mathrm{a}$ ), the measured current density is due to the double-layer charging and charge transfer correlated to $\mathrm{Pd}$ deposition (nucleation and initial growth). The current density transient reaches values as high as $-37 \mathrm{~mA} \mathrm{~cm}^{-2}$, as shown in Figure $1 \mathrm{c}$, which is almost three orders of magnitude higher than the current density of about $-30 \mu \mathrm{Acm}^{-2}$ measured during the growth pulse with potential $U_{\mathrm{g}}=220 \mathrm{mV}$ (Figure $1 \mathrm{~b}$ ). The electrochemically active surface area of Pd NPs (S), which was determined both from the charge of $\mathrm{Pd}$ monoxide reduction (shown in Figure $1 \mathrm{e}$ ) and $\mathrm{CO}$ stripping (shown in Figure $1 \mathrm{f}$ ), is plotted versus the charge transferred during $\mathrm{Pd}$ deposition $(\mathrm{Q})$ (mainly contributed by the growth pulse) in Figure $1 \mathrm{~d}$. Through fitting to a power law, the active area is found to be proportional to the $2 / 3$ power of the transferred charge $\left(S \sim Q^{2 / 3}\right)$.

The morphology of Pd NPs on HOPG was characterised by TM-AFM (Figure 2). The 3D particles tend to be located at the step edges, which can be explained by the stronger bonds at step edges compared with those at the terraces. Furthermore, the bright and round Pd NPs contain small irregular structures that are due to the roughening of the surface formed during the oxidation pulse.

The particle densities and corresponding root-mean-square (RMS) deviations are shown in Table 1. For all samples, the particle densities are of the same order of magnitude (ca. $\left.10^{9} \mathrm{~cm}^{-2}\right)$. The samples with shorter growth time (1-20 s) have higher particle densities compared with those growing longer (50-200 s).

The particle width obtained in AFM images was much larger than the true value because it was convoluted with the tip width during image acquisition. ${ }^{[21]}$ Therefore, particle size was evaluated by the height obtained from AFM images (shown in 

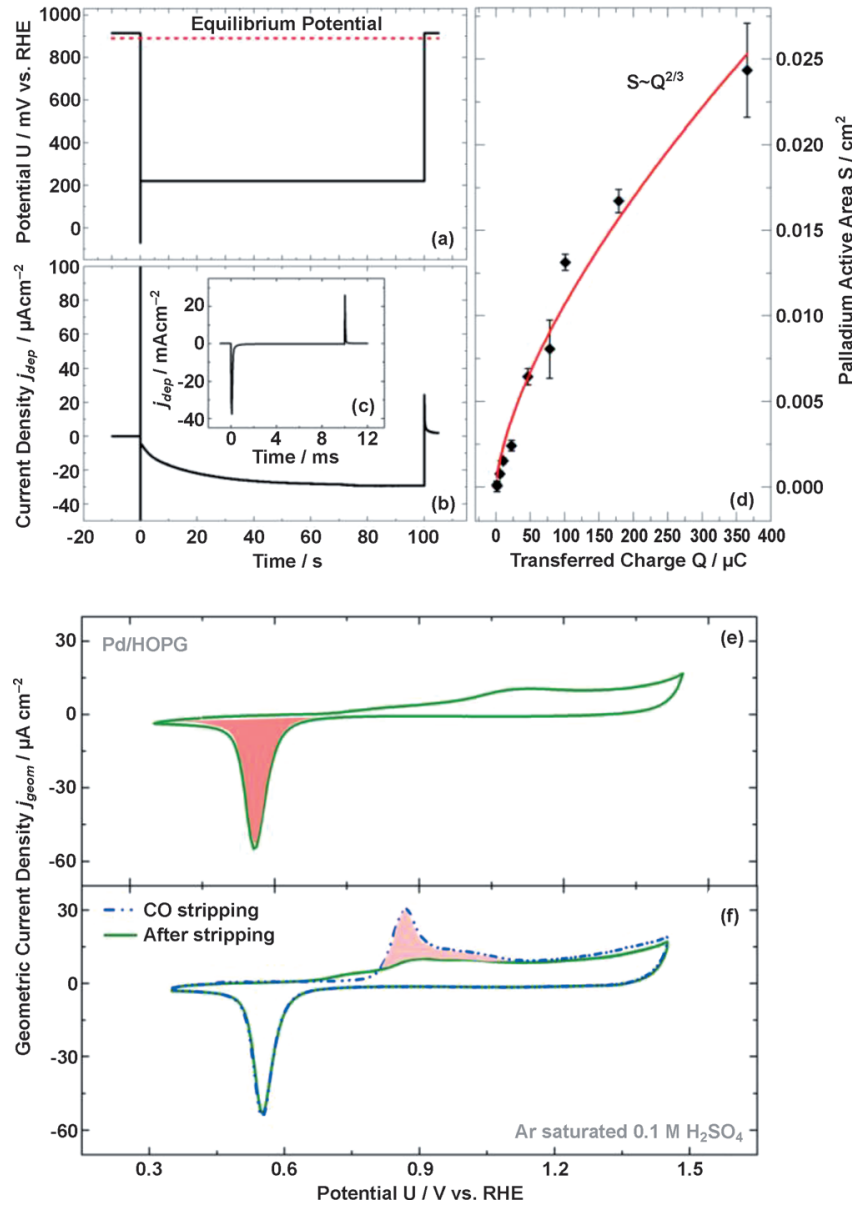

Figure 1. Double-pulse deposition with nucleation potential $U_{\mathrm{n}}=-70 \mathrm{mV}$ and growth potential $U_{g}=220 \mathrm{mV}$. The equilibrium potential of $\mathrm{Pd}^{2+} / \mathrm{Pd}$ (for $\mathrm{c}\left(\mathrm{Pd}^{2+}\right)$ at $\left.0.5 \mathrm{~mm}\right)$ is approximately $890 \mathrm{mV}$ (red dashed line). The graphs show: a) the applied potential versus time, the duration of the nucleation pulse and the growth pulse are $10 \mathrm{~ms}$ and $100 \mathrm{~s}$, respectively; b) the corresponding measured current density; c) the current density measured during the nucleation pulse with high temporal resolution; d) the active surface area of deposited Pd NPs versus the charge transferred during deposition; the area is proportional to the $2 / 3$ power of the transferred charge (red fit line); e) the $\mathrm{CV}$ of $\mathrm{Pd} / \mathrm{HOPG}$ in Ar saturated $0.1 \mathrm{M} \mathrm{H}_{2} \mathrm{SO}_{4}$ at a scan rate of $50 \mathrm{mV} \mathrm{s}^{-1}$; ) the CVs of Pd/HOPG in CO stripping and after stripping in Ar saturated $0.1 \mathrm{M} \mathrm{H}_{2} \mathrm{SO}_{4}$ at a scan rate of $50 \mathrm{mV} \mathrm{s}^{-1}$. In both (e) and (f), the transferred charge is proportional to the integrated $\mathrm{CV}$ over the shaded region.

Table 1. Particle density, average particle size and their root-mean-square deviation as evaluated from TM-AFM images. Three frames for each sample with an actual area of $2 \mu \mathrm{m} \times 2 \mu \mathrm{m}$ were used for analysis.

$t_{\mathrm{g}} \quad$ Particle density RMS deviation Average particle RMS deviation [s] $\left[10^{9} \mathrm{~cm}^{-2}\right]$ of particle size $[\mathrm{nm}]$ ofparticle

\begin{tabular}{|c|c|c|c|c|}
\hline & & density [\%] & & size [\%] \\
\hline 1 & 4.7 & 12.9 & 2.6 & 28.0 \\
\hline 5 & 5.0 & 12.8 & 6.0 & 22.0 \\
\hline 10 & 4.6 & 18.2 & 7.6 & 21.4 \\
\hline 20 & 3.7 & 25.7 & 8.3 & 16.5 \\
\hline 50 & 1.89 & 5.4 & 11.2 & 19.5 \\
\hline 100 & 1.72 & 4.5 & 13.4 & 14.7 \\
\hline 200 & 1.8 & 23.0 & 17.4 & 17.0 \\
\hline
\end{tabular}

Table 2). The average height of NPs, varying from approximately 2 to $20 \mathrm{~nm}$, as a function of the growth time, is shown in
Table 2. Tafel slope for ORR at low and high current-density regions and specific current density at $0.73 \mathrm{~V}$ in mass-transfer corrected Tafel plot.

Sample Tafel Slope $\left[\mathrm{mV} \mathrm{dec}^{-1}\right]^{[a]} \quad$ Specific current density Region 1 Region 2 at $0.73 \mathrm{~V}\left[\mathrm{~mA}^{-1} \mathrm{~cm}^{-2}\right]$

$\begin{array}{llll}\text { Pd wire } & -47 & -88 & 2.74\end{array}$

$\mathrm{Pd} / \mathrm{HOPG} t_{\mathrm{g}}=100 \mathrm{~s} \quad-42 \quad-97 \quad 2.07$

$\mathrm{Pd} / \mathrm{HOPG} t_{\mathrm{g}}=50 \mathrm{~s} \quad-49 \quad-123 \quad 2.03$

$\mathrm{Pd} / \mathrm{HOPG} t_{\mathrm{g}}=25 \mathrm{~s} \quad-69 \quad-122 \quad 0.21$

$\mathrm{Pd} / \mathrm{HOPG} t_{\mathrm{g}}=10 \mathrm{~s} \quad-72 \quad-125 \quad 0.21$

[a] Region 1 corresponds to low current densities and Region 2 to high current densities.

Figure 3. The data fit well with a power function such that the height is proportional to the cube root of growth duration $\left(\sim t_{\mathrm{g}}{ }^{1 / 3}\right)$.

\subsection{Catalytic Activity Measurements}

\subsubsection{Hydrogen Evolution Reaction}

HER on Pd/HOPG was investigated by using linear-sweep voltammetry in $\mathrm{H}_{2}$ saturated $0.1 \mathrm{M} \mathrm{H}_{2} \mathrm{SO}_{4}$. Figure $4 \mathrm{a}$ shows the specific current density of $\mathrm{Pd} / \mathrm{HOPG}$ samples and a $\mathrm{Pd}$ wire as a reference for HER in the cathodic scans. The data were corrected for a small contribution from the capacitive charging current of the HOPG substrate. Figure $4 \mathrm{~b}$ shows the corresponding Tafel plots. During these HER/HOR voltammetric measurements, the open circuit potential (OCP) can be approximated from the potential value corresponding to the lowest current density in the logarithmic plot, which is close to zero current. The OCP for a bulk Pd surface is at $48 \mathrm{mV}$. However, on the samples of Pd/HOPG with an average radius $\left(r_{\text {avg. }}\right)$ of NPs larger than $8 \mathrm{~nm}$, the OCP of HER/HOR is around $0 \mathrm{mV}$, which is approximately $50 \mathrm{mV}$ more negative compared with that of bulk Pd. On the other hand, on samples of Pd/HOPG with $r_{\text {avg. }}$ smaller than $8 \mathrm{~nm}$, the OCP of HER/HOR shifts positively, and becomes even more positive than that of bulk Pd (as the sample with $1 \mathrm{~s}$ growth pulse in Figure $4 \mathrm{~b}$ ).

Pd NPs show an enhanced specific current density in HER with reducing particle size. The specific current density of $\mathrm{Pd}$ NPs with $r_{\text {avg. }}=2.4 \mathrm{~nm}$ is approximately four times higher than that of the sample with $r_{\text {avg. }}=13.8 \mathrm{~nm}$ at $-150 \mathrm{mV}$. However, the current density of bulk Pd is nearly the same as that of $\mathrm{Pd}$ NPs at the smallest size. Pd/HOPG samples with larger nanoparticles show lower current densities as compared with those of Pd bulk.

\subsubsection{Oxygen Reduction Reaction}

The activity of Pd/HOPG for ORR was studied by using linearsweep voltammetry in $\mathrm{O}_{2}$ saturated $0.1 \mathrm{M} \mathrm{H}_{2} \mathrm{SO}_{4}$ under stagnant conditions. Figure 5 shows the current density-voltage plots of bulk Pd and Pd/HOPG samples during ORR. The current densities are normalised to the geometric surface area of the substrate. From the onset potential at approximately $820 \mathrm{mV}$, the current increases exponentially at first, until the 

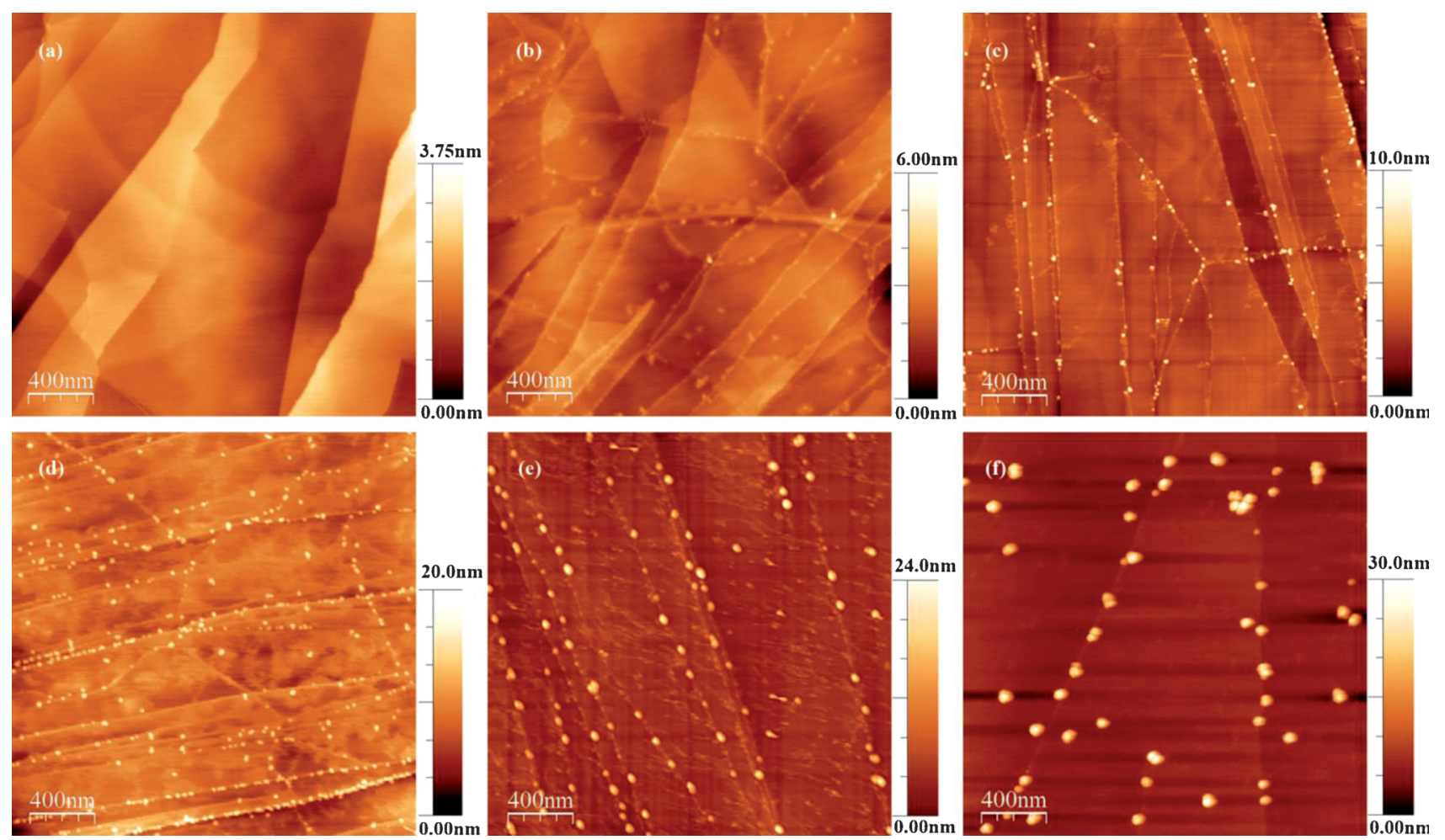

Figure 2. TM-AFM images of HOPG and Pd/HOPG surfaces. a) HOPG surface oxidised at $5.73 \mathrm{~V}$ for 100 ss in oxygen-saturated $0.1 \mathrm{M} \mathrm{H}_{2} \mathrm{SO}_{4}$. b) $\mathrm{Pd} / \mathrm{HOPG}$ with $t_{\mathrm{g}}=1 \mathrm{~s}$. c) Pd/HOPG with $t_{\mathrm{g}}=5 \mathrm{~s}$. d) Pd/HOPG with $t_{\mathrm{g}}=10 \mathrm{~s}$. e) Pd/HOPG with $t_{\mathrm{g}}=50 \mathrm{~s}$. f) Pd/HOPG with $t_{\mathrm{g}}=200 \mathrm{~s}$.

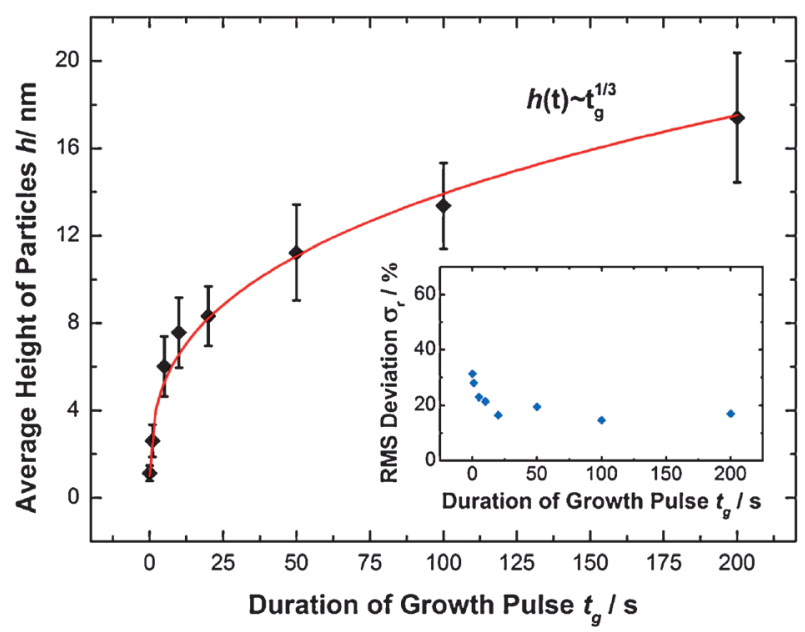

Figure 3. Average height of NPs versus the duration of the growth pulse. The inset shows the standard deviations in percentage with respect to the average height. The average height is proportional to $t_{\mathrm{g}}{ }^{1 / 3}$.

mass transport of $\mathrm{O}_{2}$ becomes increasingly prevalent. The halfwave potential shifts to negative direction with particle size reduction; the potential at which a maximum in the current due to mass transport occurs, also negatively shifts due to the decreasing Pd surface area. To compare the activities for ORR at small overpotentials, the current densities were normalised to the active area of $\mathrm{Pd}$; the data were analysed by using Equation (1): $\frac{1}{j}=\frac{1}{j_{\mathrm{k}}}+\frac{1}{j_{\mathrm{d}}}$

where $j$ is the measured current density, $j_{\mathrm{k}}$ and $j_{\mathrm{d}}$ are kinetic and diffusion-limited current densities, respectively. Under the stagnant electrolyte conditions used in these studies, the fact that $j_{d}$ is actually a function of time is neglected during the analysis. The resulting mass-transfer-corrected Tafel plots of ORR are shown in Figure 6. Two regions with distinct Tafel slopes can be observed (shown in Table 2). The specific kinetic currents for bulk Pd and Pd NPs at $0.73 \mathrm{~V}$ are also listed in Table 2. Pd NPs show a lower specific current for ORR compared with bulk Pd at this potential, and the specific current decreases with decreasing particle size. A negatively correlated size-dependent activity of Pd NPs for ORR is thus observed.

\subsection{Stability Measurement}

To investigate the dependence of the degeneration rate of the $\mathrm{Pd}$ active surface area on the $\mathrm{pH}$ in acidic solution, for one $\mathrm{Pd} /$ HOPG sample $\left(t_{\mathrm{n}}=0.01 \mathrm{~s}\right.$ and $\left.t_{\mathrm{g}}=20 \mathrm{~s}\right)$ five sets of CV scans in three $\mathrm{Ar}$ purged electrolytes were applied alternately. The lower and upper potentials for the CV scans in different electrolytes are given in the Experimental Section. The surface area was calculated from the charge transferred during PdO reduction. Figure 7 shows the continuous decrease of the surface area during the potential cycles, assuming the same areal charge density for $\mathrm{PdO}$ reduction at the different $\mathrm{pH}$ values (an assumption justified by the similar values obtained at $\mathrm{pH} 4.35$ 

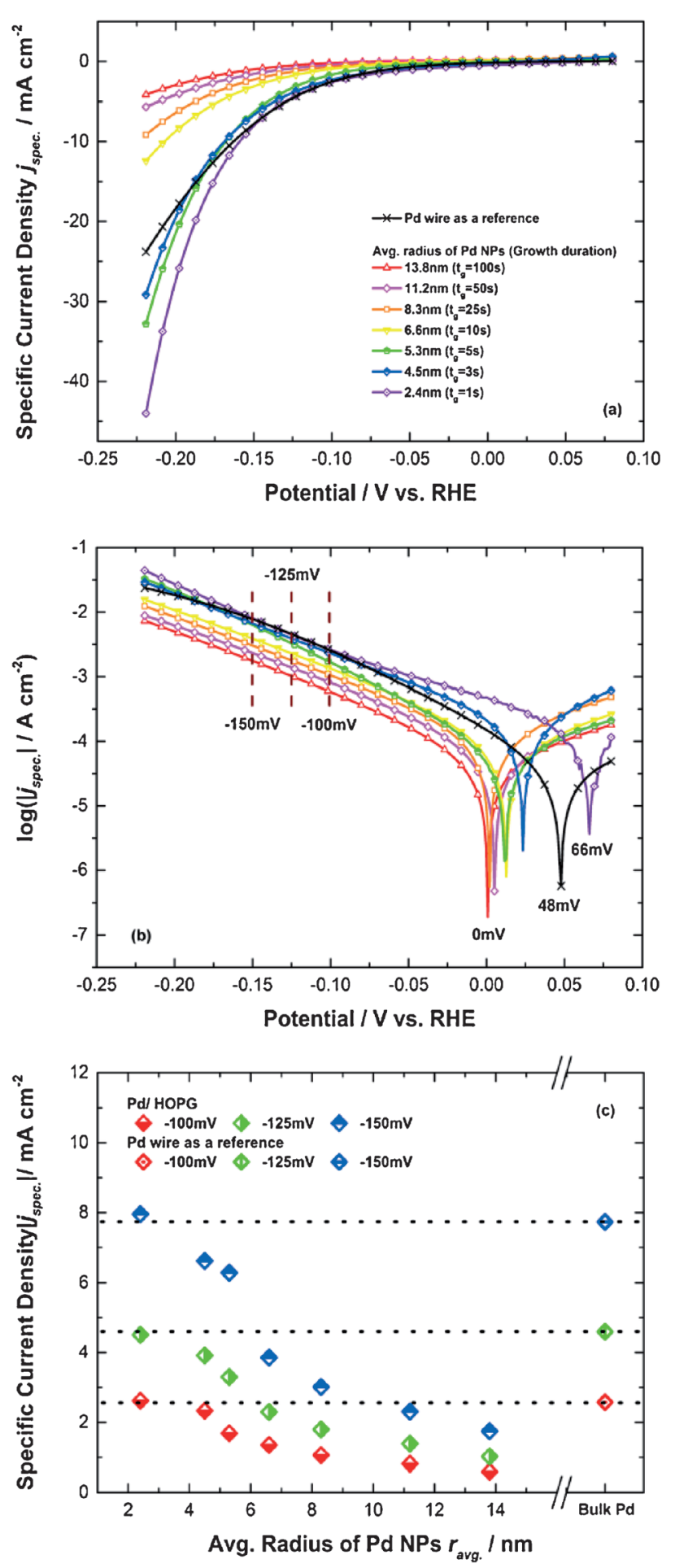

Figure 4. a) Specific current density, b) Tafel plot, and c) specific current density at selected potentials for HER of a Pd wire and Pd/HOPG samples with different average particle radii. The current density is normalised to the Pd active area obtained from the charge transferred during $\mathrm{Pd}$ monoxide reduction. The selected potentials in (c) are $-100,-125$ and $-150 \mathrm{mV}$, respectively. The $r_{\text {avg. }}$ of Pd NPs was estimated from the duration of the growth pulse based on the curve shown in Figure 3.

and the subsequent experiments at $\mathrm{pH} 1$ ). The $\mathrm{Pd}$ surface area decreases much faster in $0.1 \mathrm{M} \mathrm{H}_{2} \mathrm{SO}_{4}$ than in the other solutions. In $0.1 \mathrm{M} \mathrm{Na}_{2} \mathrm{SO}_{4}$, the Pd surface area remains almost con-

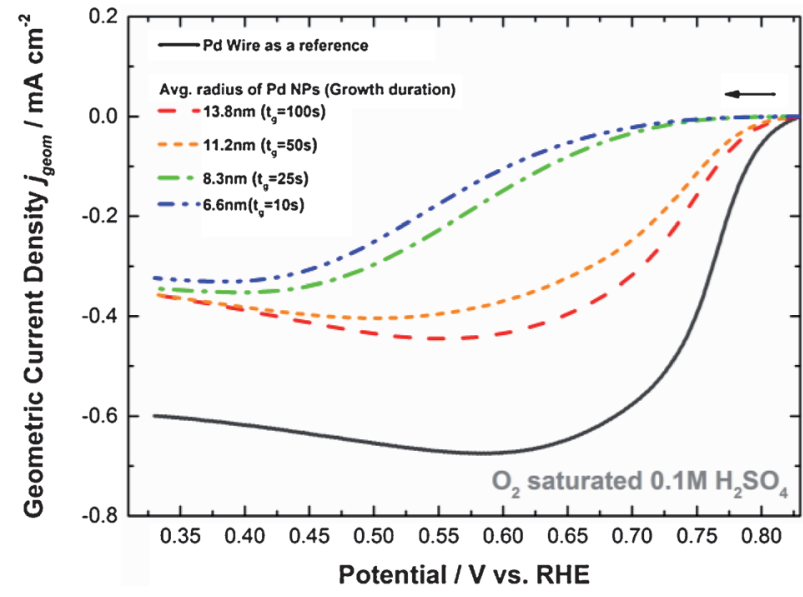

Figure 5. Current-voltage curves of bulk Pd and Pd/HOPG samples with decreasing potential in $\mathrm{O}_{2}$ saturated $0.1 \mathrm{M} \mathrm{H}_{2} \mathrm{SO}_{4}$. The arrow indicates the direction of the potential scan. Scan rate is $20 \mathrm{mV} \mathrm{s}^{-1}$.

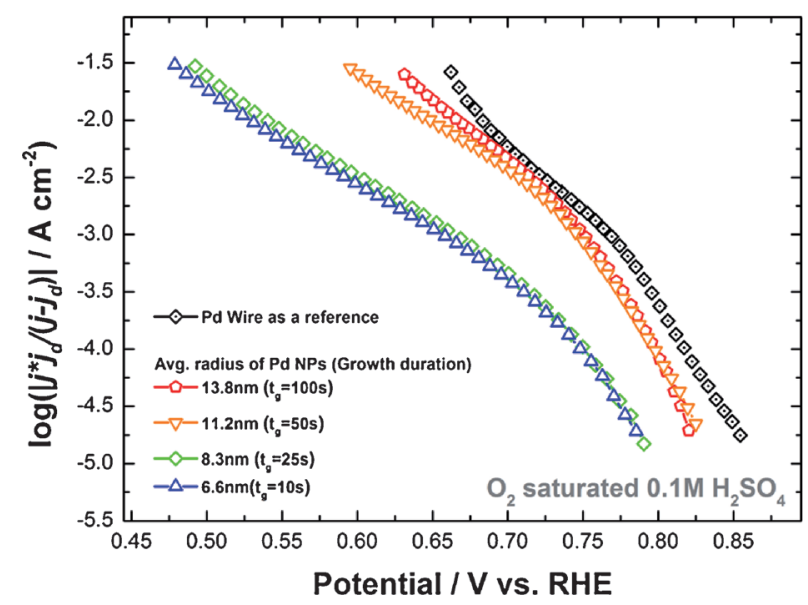

Figure 6. Mass-transfer-corrected Tafel plot of ORR for Pd wire and Pd/HOPG samples with different average particle sizes. The kinetic current density, which is normalised to the Pd active area, is obtained from Equation (1).

stant. In the $\mathrm{pH} 3$ electrolyte, the $\mathrm{Pd}$ surface area decreases, but the reduction rate is much lower than that in $0.1 \mathrm{M} \mathrm{H}_{2} \mathrm{SO}_{4}$.

The continuous decrease of $\mathrm{Pd}$ surface area in a $\mathrm{pH} 3$ electrolyte was studied in more detail. To a Pd/HOPG $\left(t_{\mathrm{g}}=100 \mathrm{~s}\right)$ sample, potential cycles were applied in the range of 0.182 to -1.332 Vvs. SHE in an $\mathrm{Ar}$ saturated $\mathrm{Na}_{2} \mathrm{SO}_{4}(0.1 \mathrm{M})+\mathrm{H}_{2} \mathrm{SO}_{4}$ $(x \mathrm{mM})$ solution $(\mathrm{pH} 3)$. Before potential cycling and after 50 , $100,150,200$, and 250 cycles, the morphology of this sample was investigated by AFM (shown in Figure 8). The electrochemically determined active surface area of Pd NPs for this sample decreases exponentially with the number of potential cycles, which is shown in Figure 9. The surface area of Pd NPs on HOPG immediately after deposition was $8.87 \times 10^{-3} \mathrm{~cm}^{2}$. After 100 potential cycles, only $12.3 \%$ of the surface area remained, and after 250 cycles, the surface area reduced to $0.28 \%$ of the initial value. Before potential cycling, Pd NPs anchor at edges and defects of the HOPG surface; the average height of the NPs [shown in Figure 9(2)] was (13.3 \pm 2.0$) \mathrm{nm}$; 


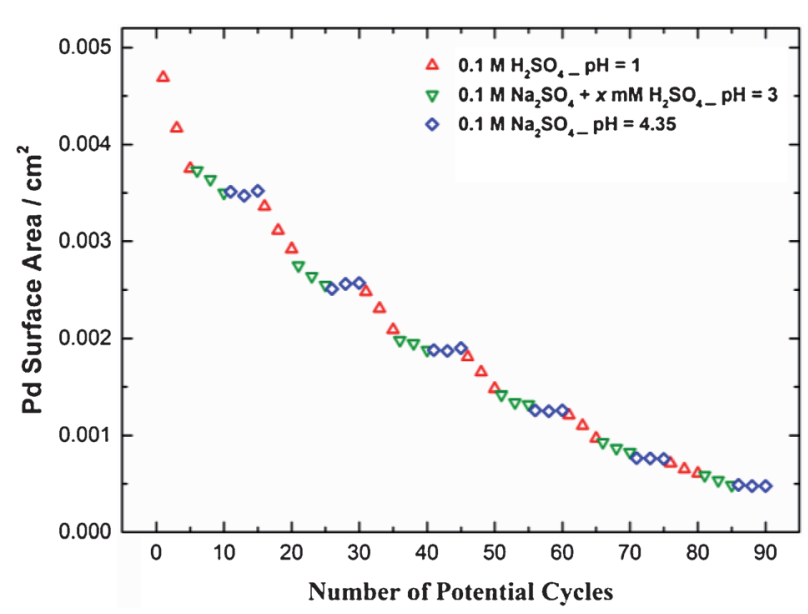

Figure 7. Stability measurement of one Pd/HOPG sample (prepared with a nucleation pulse of $10 \mathrm{~ms}$ and a growth pulse of $20 \mathrm{~s}$ ) in three Ar-purged electrolytes with different $\mathrm{pH}$ values. Five potential cycles were applied to the sample each time in one electrolyte. The surface area is evaluated from the transferred charge of $\mathrm{PdO}$ reduction. Potential ranges were 0.3-1.45 V vs. SHE in $0.1 \mathrm{M} \mathrm{H}_{2} \mathrm{SO}_{4}(\mathrm{pH} 1), 0.182-1.332 \mathrm{~V}$ vs. SHE in $0.1 \mathrm{M} \mathrm{Na}_{2} \mathrm{SO}_{4}+x \mathrm{mM}$ $\mathrm{H}_{2} \mathrm{SO}_{4}\left(\mathrm{pH} 3\right.$ ) and $0.102-1.252 \mathrm{~V}$ vs. SHE in $0.1 \mathrm{M} \mathrm{Na}_{2} \mathrm{SO}_{4}(\mathrm{pH} 4.35$ ).

and the HOPG terraces are smooth, with very few irregular structures. After 50 potential cycles, agglomeration of Pd NPs can be observed [the average height of NPs decreases to $(10.1 \pm 1.4) \mathrm{nm}]$ and irregular structures, which are much smaller than the Pd NPs, appear on the terraces of HOPG. With further increasing the number of potential cycles, the average height of NPs, as observed by AFM, decreases to approximately $8 \mathrm{~nm}$, and then remains constant. The width of the particle height distribution increased from $\pm 14.7 \%$ of the average initially to $\pm 21.1 \%$ of the average. Finally, irregular structures on the substrate become clearer, and their sizes are in the range of 0.5 to $2.5 \mathrm{~nm}$.

\section{Discussion}

\subsection{Particle Growth on HOPG}

The potentiostatic double-pulse technique can be used to control particle size and density by separating the processes of particle nucleation and particle growth. If the nucleation of new NPs occurs progressively during growth, the growth duration of individual particles will be distributed over time, and the size distribution will be broadened. If, in contrast, nucleation occurs almost instantaneously, and no further nuclei form during particle growth, the growth duration of each particle will be almost equal, and the broad size distribution caused by various growth durations will be avoided.

In the experiment described in this paper, reactant ions at the electrode surface are rapidly depleted in the nucleation pulse, and very few of them can be supplied from the bulk solution in such a short time interval. The density of NPs on the substrate should remain similar for different samples when the nucleation is carried out under the same conditions. The particle densities of all samples prepared with different growth durations are approximately $10^{9} \mathrm{~cm}^{-2}$. With increasing duration of
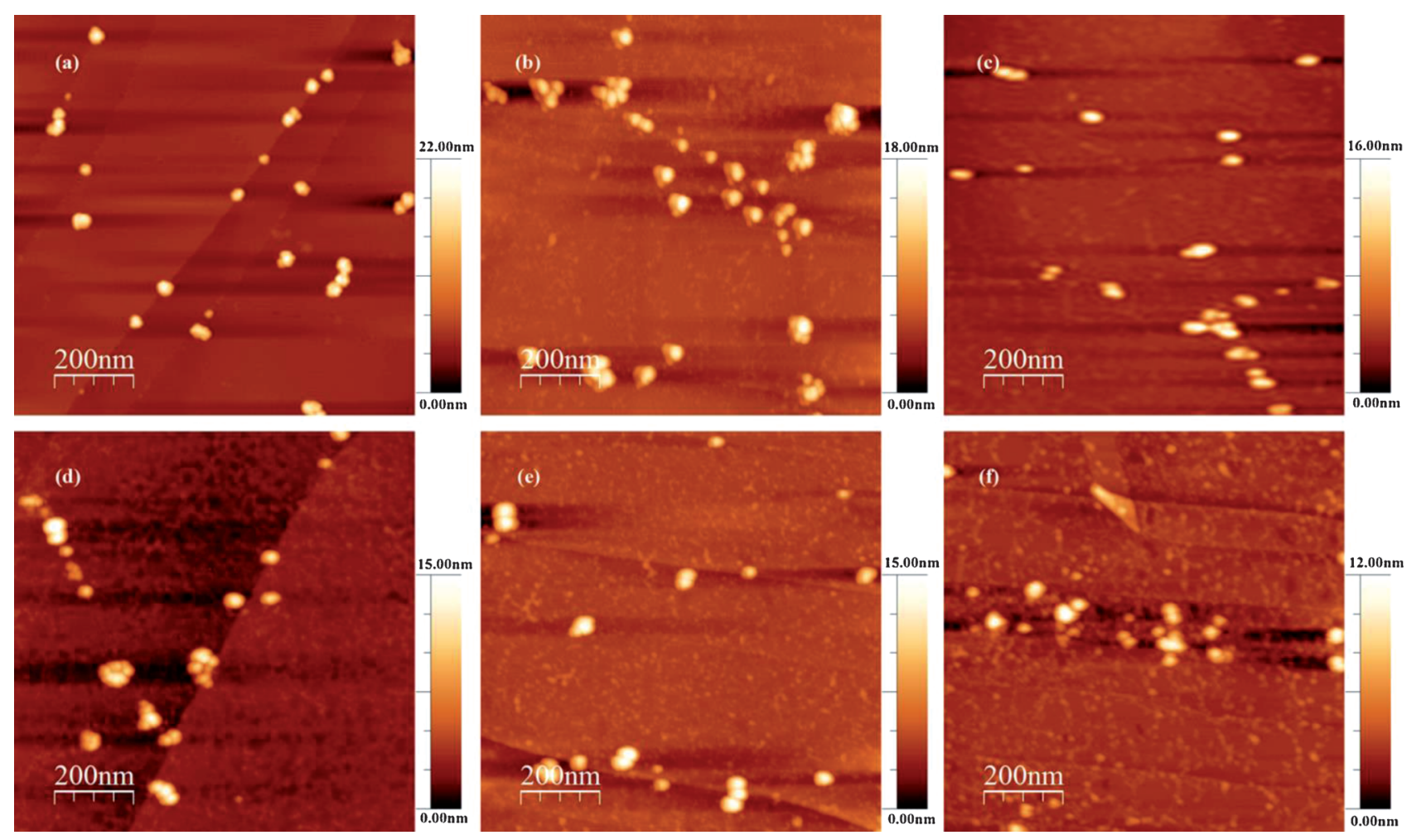

Figure 8. TM-AFM images of Pd NPs on HOPG during the stability measurement. Images were obtained a) before potential cycles and after b) 50 , c) 100 , d) 150, e) 200 , and f) 250 cycles. 

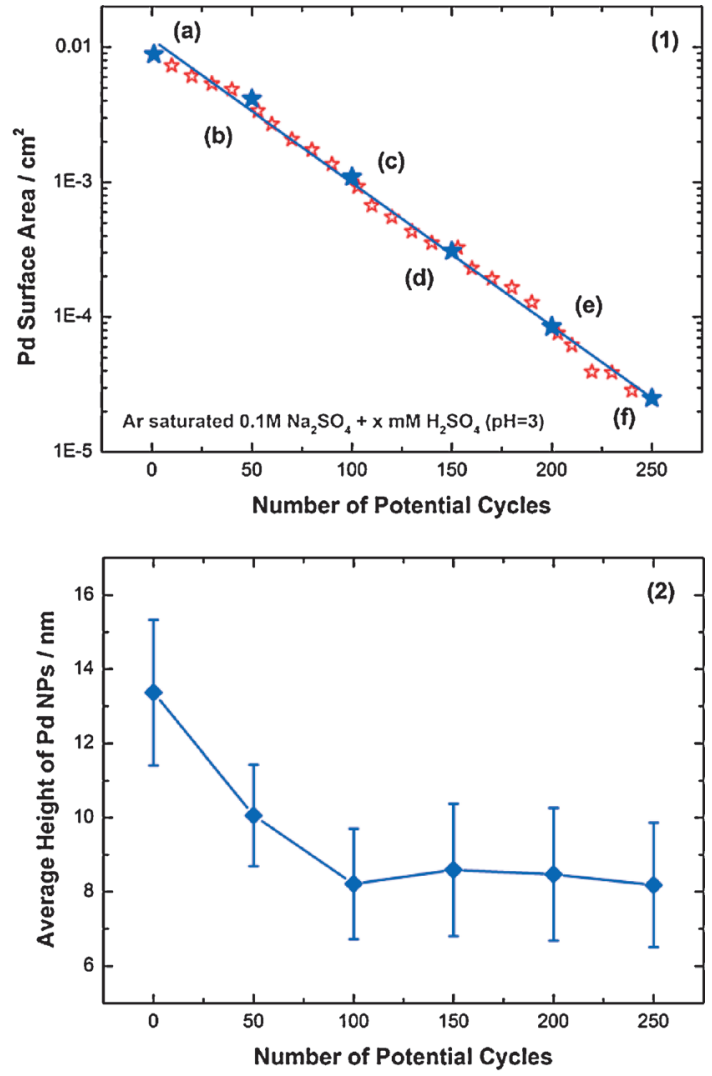

Figure 9. Stability measurement of one Pd/HOPG sample (prepared with a nucleation pulse of $10 \mathrm{~ms}$ and a growth pulse of $100 \mathrm{~s}$ ) in a $0.1 \mathrm{M}$ $\mathrm{Na}_{2} \mathrm{SO}_{4}+x \mathrm{mM} \mathrm{H}_{2} \mathrm{SO}_{4}(\mathrm{pH} 3)$ solution. Potential cycles in the range from 0.182 to $1.332 \mathrm{~V}$ vs. SHE were applied to the sample for in total 250 cycles. 1) The decrease of Pd surface area during potential cycles; before the first potential cycle and after 50, 100, 150, 200 and 250 cycles (marked as blue stars in the graph), ex situ AFM images were acquired under dry conditions. 2) The average heights of Pd NPs before potential cycles and after 50, 100, 150, 200 and 250 cycles. Particle heights were evaluated from the AFM images acquired in each ex situ AFM imaging process. Three frames for each sample with an actual area of $2 \mu \mathrm{m} \times 2 \mu \mathrm{m}$ were used in the evaluation. The RMS deviations are in the range of $14.7-21.1 \%$.

the growth pulse, the particle densities, as determined by AFM, do not increase or remain constant, but decrease from $(4.8 \pm 0.2) \times 10^{9} \mathrm{~cm}^{-2}$ in the short-growth-pulse cases down to $(1.8 \pm 0.1) \times 10^{9} \mathrm{~cm}^{-2}$ in the long-growth-pulse cases. The agglomeration of neighbouring NPs on the HOPG surface, which can be observed in the AFM images, takes place significantly during particle growth.

Pd NPs on HOPG are approximately hemispherical. This statement is confirmed by the observation that the electrochemically determined active surface area of particles $(S)$ is proportional to the $2 / 3$ power of the charge transferred during electrodeposition $\left(Q^{2 / 3}\right)$. The low interfacial energy between the metal particle and the coordinatively saturated graphite plane surface (interaction is mainly due to van der Waals forces) means that the growth of metal particles on HOPG follows the Volmer-Weber mode, in which 3D metal particles grow uniformly in all directions. ${ }^{[22]}$ The height of hemispherical particles determined from AFM images is therefore equivalent to the radius.
The metal particle growth on HOPG was discussed in detail by Penner and co-workers. ${ }^{[20 \mathrm{~b}, \mathrm{~d}]}$ If the particles grow under kinetic control, their radii increase in direct proportion to the deposition time $\left(r_{0}(t) \sim t\right)$. Under the ideal conditions of kinetically controlled growth, a concentration gradient of $\mathrm{Pd}^{2+}$ ions does not exist in front of the electrode surface. If a particle grows under hemispherical diffusion-control, the radius of this particle increases proportionally with the cube root of time $\left(r_{0}(t) \sim t^{1 / 3}\right)$. This model is established on the precondition of the absence of interparticle diffusional coupling, with only a hemispherical depletion layer surrounding the particle. If the depletion layers of neighbouring particles overlap strongly, the particle-decorated electrode surface can be considered as flat with a planar depletion layer. The particles will then grow according to $r_{0}(t) \sim t^{1 / 2}$. In the experiments conducted in this work, a growth overpotential was carefully selected to form a hemispherical depletion layer surrounding each particle as well as to avoid the diffusional coupling. The deposition current was observed to be nearly invariant in time, which can be identified as constant current growth. The radii of the particles increase under these conditions, as explained above, with the cube root of time according to Equation (2):

$r_{0}(t)=\left[\frac{3}{2} \frac{i_{\mathrm{dep}} M t}{z \pi \rho F N}\right]^{\frac{1}{3}}$

where $i_{\text {dep }}$ is the deposition current, $M$ is the molar weight of the metal, $\rho$ is its density, $z$ is the number of electrons transferred per metal ion, $N$ is the nuclei density and $F$ is Faraday's constant. ${ }^{[20 b]}$ The growth of each particle in this mechanism is limited by diffusion. However, the depletion layer is reduced to a small scale. The influence of interparticle diffusion coupling is significantly weakened, or even eliminated. The proportionality of average height of Pd NPs $(h)$ and cube root of growth duration $\left(t_{\mathrm{g}}{ }^{1 / 3}\right)$ demonstrates that the growth of Pd NPs follows the constant current mode (cf. Figure 3). However, the interparticle diffusion coupling cannot be eliminated completely. The RMS deviations are in the range of $14-28 \%$ when the growth duration $t_{\mathrm{g}}$ is larger than $1 \mathrm{~s}$, which is much larger than the value of $10 \%$ or less predicted by Liu et al. ${ }^{[20 \mathrm{~d}]}$ for particles in the range from $50 \mathrm{~nm}$ to $2 \mu \mathrm{m}$.

\subsection{OCP of HER/HOR on Pd Electrode}

Electrochemical studies with $\mathrm{Pd}$ as the electrode material are often obstructed in acidic media by the extraordinary phenomenon of hydrogen absorption. ${ }^{[23 a, b]}$ The situation becomes even more complex when the potential is in the range for HER such that three hydrogen-related reactions-adsorption, absorption and evolution-take place at the same time. Hydrogen absorption is present in the potential range between 70 and $300 \mathrm{mV}$ in $0.1 \mathrm{M} \mathrm{H}_{2} \mathrm{SO}_{4}$ and forms palladium hydride $\left(\mathrm{PdH}_{x}\right) \cdot{ }^{[24]}$ At potentials more negative than $70 \mathrm{mV}$, underpotential hydrogen adsorption, and at potentials below $0 \mathrm{~V}$, hydrogen evolution are also present. ${ }^{[25]}$ It has been reported that the two phases of $\mathrm{PdH}_{x}, \alpha-\mathrm{PdH}_{x}$ and $\beta-\mathrm{PdH}_{x}$, have different OCP values in the 
same solution. The $\alpha-\mathrm{PdH}_{x}$ phase, which is stable up to a hydrogen saturation limit of an atomic ratio of $\mathrm{H} / \mathrm{Pd}=0.025 \pm 0.005$, shows an OCP of $(49.5 \pm 0.5) \mathrm{mV}$ in mixtures of hydrogen-saturated sulfuric acid and sodium sulfate from $\mathrm{pH} 0.84$ to $1.8 .{ }^{[26]}$ When increasing the atomic ratio of $\mathrm{H} / \mathrm{Pd}$ above $0.025 \pm 0.005$, the $\beta-\mathrm{PdH}_{x}$ phase is present so that the two phases are in equilibrium up to a maximum $\mathrm{H} / \mathrm{Pd}$ ratio of about $0.62-0.67,{ }^{[24]}$ then the $\mathrm{PdH}_{x}$ will be in the pure $\beta$-phase. The OCP of pure $\beta$ $\mathrm{PdH}_{x}$ is at $0 \mathrm{~V}$. With a H/Pd atomic ratio of 0.03 to 0.36 , both the $\alpha$ and $\beta$ phases coexist and the OCP is determined by that of the $\alpha$ domains. For a $\mathrm{H} / \mathrm{Pd}$ ratio of between 0.36 and 0.67 , the potential is a function of the hydrogen content of the Pd. ${ }^{[26]}$

In the HER experiments, a potential sweep in the cathodic direction was applied to the working electrode. An electrocatalytically promoted hydrogen absorption proceeds on the $\mathrm{Pd}$ before or during the evolution of hydrogen molecules. The absorption rate of hydrogen into the Pd bulk is controlled by diffusion of hydrogen atoms. ${ }^{[27]}$ The diffusion coefficients of hydrogen in $\mathrm{Pd}$ are in the order of $10^{-7} \mathrm{~cm}^{2} \mathrm{~s}^{-1}$ in the $\alpha$ phase and in the order of $10^{-6} \mathrm{~cm}^{2} \mathrm{~s}^{-1}$ in the $\beta$ phase. ${ }^{[28]}$ For sufficiently small particle sizes, the diffusion limitation is eliminated, meaning that the hydrogen atoms can permeate the Pd NPs quickly and quasi-freely. ${ }^{[29]}$ The $U_{\text {ocp }}=48 \mathrm{mV}$ of HER/HOR measured at the bulk Pd indicates that the $\mathrm{PdH}_{x}$ at bulk Pd surface is in the $\alpha$-phase or $(\alpha+\beta)$-mixed phase, with an atomic ratio of $\mathrm{H} / \mathrm{Pd}$ lower than 0.36 . The OCP at Pd/HOPG with $r_{\text {avg. }}>8 \mathrm{~nm}$ is around $0 \mathrm{~V}$, which approaches the OCP of pure $\beta-\mathrm{PdH}_{x}$. This indicates that the Pd NPs are in the $\beta$-phase. The OCP at Pd/ HOPG samples with $r_{\text {avg. }}<8 \mathrm{~nm}$ shows a tendency of positive shifting; even the OCP of Pd/HOPG with $r_{\text {avg. }}=2.4 \mathrm{~nm}$ is at $66 \mathrm{mV}$, which is more positive than that of bulk Pd. Establishing the reason for this behaviour will be the subject of further studies. According to Figure 10, one assumption is that the positively shifted OCP can be explained by a lower hydrogen content in the small Pd NPs. A lower hydrogen content (lower $\mathrm{H}$ activity) in the Pd will lead to a positive shift of the equilibrium potential and thus the OCP, as long as it is determined by the $\mathrm{H}$ absorption equilibrium. A lower $\mathrm{H}$ content is supported by previous results: Kolb and Baldauf ${ }^{[8 \mathrm{~d}]}$ studied the hydrogen absorption of Pd overlayers on Au single crystals. They suggested that hydrogen absorption occurs only for Pd films thicker than $2 \mathrm{ML}$. When the Pd films are thinner than $10 \mathrm{ML}$, the atomic ratio of $\mathrm{H} / \mathrm{Pd}$ is less than 0.5 ; only once the thickness of Pd films exceeds $20 \mathrm{ML}$ can the atomic ratio of $\mathrm{H} / \mathrm{Pd}$ be larger than 0.6 . The thickness of films can be considered to be analogous to the radius of NPs, even though the NP on HOPG has a different lattice constant compared with $\mathrm{Pd} / \mathrm{Au}$.

\subsection{Electrocatalytic Activity for HER}

The HER in acidic media usually follows the Volmer-Tafel mechanism when the coverage of adsorbed hydrogen atoms is low, and the Volmer-Heyrowsky mechanism when the coverage is high. ${ }^{[30 a, b]}$ When the whole process is limited by the Volmer reaction, the Tafel slope will be expected to be $-118.3 \mathrm{mV} \mathrm{dec}^{-1}$; this is in agreement with the Tafel slopes of

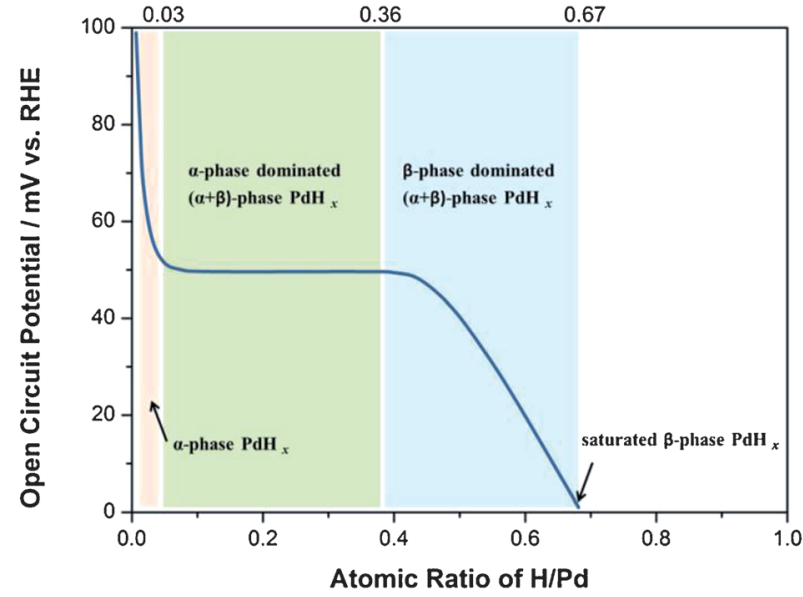

Figure 10. Variation of open circuit potential (OCP) of $\mathrm{PdH}_{x}$ in $\mathrm{H}_{2}$ saturated sulfuric acid- sodium sulfate mixtures from $\mathrm{pH} 0.84$ to 1.8 with the change of atomic ratio of $\mathrm{H} / \mathrm{Pd}$. The OCPs of saturated $\alpha-\mathrm{PdH}_{x}$ and $\alpha$-phase dominated $(\alpha+\beta)-\mathrm{PdH}_{x}$ are $50 \mathrm{mV}$ vs. $\mathrm{RHE}$; the OCP of saturated $\beta-\mathrm{PdH}_{x}$ is $0 \mathrm{~V}$ vs. RHE. [26]

all measured samples, which were in the range of $(-120 \pm$ 15) $\mathrm{mVdec}^{-1}$.

As discussed above, the hydrogen absorption already occurs on the Pd surface at potentials more positive than the equilibrium potential of $\mathrm{HER} / \mathrm{HOR}$, such that it makes it difficult to compare the specific current densities of different $\mathrm{Pd}$ samples because of the uncertainty of surface composition. In Figure $4 c$, the current densities of Pd/HOPG samples are plotted versus the average radius, and are compared to a reference of bulk Pd. The surface composition of bulk Pd participating in the HER corresponds to $\alpha$-phase dominated $\mathrm{PdH}_{x}$, which can be concluded from its OCP value. On the other hand, the surface composition of Pd/HOPG with $r_{\text {avg. }}>8 \mathrm{~nm}$ is almost pure $\beta$-phase $\mathrm{PdH}_{x}$. The specific current density of bulk $\mathrm{Pd}$ is higher than that of Pd NPs, with $r_{\text {avg. }}>8 \mathrm{~nm}$, which indicates that the $\alpha$-phase dominated $\mathrm{PdH}_{x}$ has a higher catalytic activity than the pure $\beta$-phase $\mathrm{PdH}_{x}$. This behaviour can be explained by the expansion of the Pd lattice structure with the inclusion of hydrogen atoms. The lattice constant of Pd nanopowder has been reported to change from initially $3.898 \AA$ to $3.972 \AA$ after hydrogen absorption..$^{[31]}$ The lattice expansion is positively correlated to the number of absorbed hydrogen atoms. ${ }^{[32]}$ The presence of hydrogen atoms in the Pd lattice leads to tensile strain, which causes an upshift of the d-band centre, ${ }^{[13]}$ so that the adsorbed hydrogen can bond to the active Pd area strongly, and blocks further reaction. Kibler et al. ${ }^{[33 a, b]}$ observed the same effect for HER when comparing pure Pd with tensilestrained Pd multilayers on $\mathrm{Au}(100)$. This means that the modification of the electronic structure at the Pd surface by the absorbed hydrogen atoms does not enhance the electrocatalytic activity for HER, but weakens it. A further increase in the hydrogen content further decreases the HER activity; that is, the $\beta$-phase $\mathrm{PdH}_{x}$ is less active than the $\alpha$-phase $\mathrm{PdH}_{x}$ for HER.

The HER on the Pd/HOPG samples in pure $\beta$-phase $\mathrm{PdH}_{x}$ $\left(r_{\text {avg. }}>8 \mathrm{~nm}\right)$ shows a size-dependent activity with an increased specific current density at smaller particle sizes. This behaviour 
may, in part, be attributed to structural parameters such as the density of low coordinated atoms, steps and defects, which are sensitive to the particle size. The spillover effect of hydrogen from Pd to HOPG should also be considered, because this effect is sensitive to the interparticle distance, which becomes larger when the NPs are smaller. ${ }^{[11]}$ The specific current density of Pd NPs with $r_{\text {avg. }}<8 \mathrm{~nm}$ follows the tendency of continuously increasing with particle size reduction due to the reduced content of hydrogen in the lattice according to the positively shifted OCP as discussed above. Fewer hydrogen atoms in the $\mathrm{Pd}$ lattice will lead to lattice contraction, meaning that an enhanced activity should be observed. The specific current density of the smallest Pd NPs is nearly the same as that of bulk Pd, which indicates that the catalytic activity of Pd NPs for HER is predominantly controlled by the content of absorbed hydrogen.

\subsection{Electrocatalytic Activity for ORR}

Two distinct Tafel slopes can be observed at low and high current densities in the mass-transfer corrected Tafel plots of ORR (in Figure 6). Many authors ${ }^{[34 a, b, c]}$ have reported the values for the Tafel slope at bulk and nanostructured Pd catalysts in sulfuric acid as $(-60 \pm 10) \mathrm{mV} \mathrm{dec}^{-1}$ at low current densities and $(-120 \pm 20) \mathrm{mV} \mathrm{dec}^{-1}$ at high current densities. In this work, the values of the Tafel slope for bulk Pd and Pd NPs with large size $\left(t_{\mathrm{g}}=100 \mathrm{~s}\right)$ are less than $-60 \mathrm{mV} \mathrm{dec}^{-1}$ at low current densities and less than $-120 \mathrm{mV} \mathrm{dec}^{-1}$ at high current densities. For Pd NPs with small sizes, however, the values of the Tafel slope are close to -60 and $-120 \mathrm{mV} \mathrm{dec}^{-1}$, respectively, in the two regions. The Tafel slopes for bulk Pd and Pd NPs with large sizes at high current densities are lower than the reported values for a four-electron transfer mechanism of $\mathrm{O}_{2}$ reduction $\left(-120 \mathrm{mV} \mathrm{dec}^{-1}\right)$. This indicates the formation of some $\mathrm{H}_{2} \mathrm{O}_{2}$ during the reaction. However, the ORR on Pd/HOPG with small particle size follows the four-electron transfer mechanism (dissociative mechanism) well, and the main product is water.

A size-dependent activity of Pd NPs supported on HOPG for ORR is observed in the experiments (shown in Figure 6). This result is consistent with the work reported by Anastasopoulos et al. ${ }^{[35]}$ The Pd/HOPG samples with a growth duration longer than $50 \mathrm{~s}$, of which the average radius of NPs is larger than $10 \mathrm{~nm}$, have a similar kinetic current density to that of bulk Pd. This result indicates that Pd NPs larger than $10 \mathrm{~nm}$ act like bulk material. When the average radius of Pd NPs decreases to less than $10 \mathrm{~nm}$, however, the kinetic current density reduces rapidly. For instance, the ORR specific current density of $\mathrm{Pd} /$ HOPG samples $\left(t_{\mathrm{g}}=25\right.$ and $10 \mathrm{~s}$ ) at $0.73 \mathrm{~V}$ is less than $1 / 10$ th of that reached at a bulk Pd electrode.

Kondo et al. ${ }^{[36]}$ have reported that the activities of $\mathrm{Pd}$ lowindex planes for ORR are in the order of $\mathrm{Pd}(110)<\mathrm{Pd}(111)$ $<\operatorname{Pd}(100)$. Pd cubes, which mainly expose (100) facets, show a much higher activity than octahedral and conventional $\mathrm{Pd}$ NPs in acidic media. ${ }^{[37]}$ Otherwise, Xiao et al. ${ }^{[\mathrm{a}]}$ have reported that tailored $\mathrm{Pd}$ nanorods exposing $\mathrm{Pd}(110)$ facets show a nearly tenfold higher activity than that of Pd NPs due to the exceptionally weak interaction between $\mathrm{O}$ ad-atoms and
Pd(110) facets. The facet effect at conventional, electrodeposited Pd NPs still needs further clarification. Compared with the facet effect, the step-site and defect-site atoms play a more significant role. The active sites of $\mathrm{Pd}$ for ORR are terrace atoms. ${ }^{[36]}$ The proportion of step edges among all active sites increases with decreasing particle-size. ${ }^{[38]}$ A step-site atom, which is low coordinated, forms a stronger catalyst-adsorbate bond compared with that at a terrace-site atom, and is poisoned more quickly. In the work of Cai and co-workers, ${ }^{[39]}$ the surface roughness of Pd NPs was reduced by treating the samples with a bromide ad-/desorption process. The Pd NPs with a smoother surface then show a significantly enhanced specific activity for ORR. The size-dependent activity of Pd NPs for ORR in this work is therefore primarily attributed to the ratio of low-coordinated atoms, which is correlated to the particle size.

\subsection{Stability of Pd/HOPG in Acidic Media}

$\mathrm{Pd}$ is less stable than Pt. The oxidation of bulk Pd starts around $0.66 \mathrm{~V}$ vs. SHE in the anodic CV scan. Metal dissolution during the anodic as well as the cathodic CV scan was detected by Shrestha and co-workers ${ }^{[40]}$ when the upper potential limit was $0.80 \mathrm{~V}$ vs. SHE or above. The formation of $\mathrm{PdOH}_{\text {ads }}$ is the first step of the electro-oxidation of $\mathrm{Pd}$ in both acidic and alkaline electrolytes. In acidic solution, the formation of $\left[\mathrm{Pd}\left(\mathrm{H}_{2} \mathrm{O}\right)_{4}\right]^{2+}$ was reported for the electrochemical oxidation process of a Pd electrode. ${ }^{[41]}$ This indicates that aside from the formation of $\mathrm{PdO}$, dissolution of $\mathrm{Pd}$ into solution occurs, as also indicated by the Pourbaix diagram. ${ }^{[42]}$ In addition to metal dissolution, particle agglomeration, particle detachment and Ostwald ripening are the major degradation mechanisms for supported NPs. ${ }^{[43 a, b]}$

The ex situ AFM investigation shows that the degradation of Pd NPs supported on HOPG can be attributed to Pd dissolution, agglomeration and detachment of Pd NPs. Carbon support corrosion is also observed. After 50 potential cycles, agglomeration of neighbouring NPs is observed. After 100 cycles, the average height of the NPs decreases with the number of potential cycles until an average height of $8 \mathrm{~nm}$ is reached. Then, the average height of observable NPs remains around $8 \mathrm{~nm}$, but the absolute number of NPs reduces and it becomes increasingly difficult to find regions with abundant NPs by AFM. A slight change in the average particle size is observed, together with an inhomogeneous distribution of NPs across the surface, indicating particle detachment. After 250 cycles, $\mathrm{Pd}$ NPs can be observed only at some defects. The irregular structures on terraces of HOPG are mainly the roughened graphite caused by oxidation during anodic potential scans. However, redeposition of dissolved $\mathrm{Pd}$ atoms cannot be excluded.

\section{Conclusions}

Pd NPs were electrochemically deposited on HOPG by the potentiostatic double-pulse technique. The particle-size distributions are confined to a relatively narrow range. Pd NPs on HOPG are approximately hemispherical due to the weak inter- 
action between the substrate and deposited atoms. With an approximately constant current during the growth pulse, the radius of deposited Pd NPs is proportional to the $1 / 3$ power of the duration of growth pulse.

The electrocatalytic activity of Pd towards HER is influenced by many factors such as composition $\left(\mathrm{PdH}_{x}\right.$ phase and $\mathrm{H}$ content), lattice constant and the number of low-coordinated atoms. In this work it was shown that the hydrogen absorption causes Pd lattice strain, leading to a shift of the electron energy bands, causing a change of the adsorption enthalpy of reactants or products on the $\mathrm{Pd}$ surface and changing the reaction kinetics. The size-dependent activity of Pd NPs for ORR in this work is primarily attributed to the ratio of low-coordinated atoms, which is correlated to the particle size. The facet effect is also a key factor that needs further study.

The dissolution rate of Pd NPs is influenced by the $\mathrm{pH}$ value. The active area of Pd NPs during continuous potential cycles at low $\mathrm{pH}$ decreases exponentially. When the NPs have relatively large average sizes $\left(r_{\text {avg. }}>8 \mathrm{~nm}\right)$, the dissolution of metal atoms and NP agglomeration are the most significant factors for active area loss. When the average height of NPs is around $8 \mathrm{~nm}$, the detachment of metal NPs leads to degradation of catalysts.

The stability tests at different $\mathrm{pH}$ show that for the accurate determination of the active surface area of supported Pd NPs, a solution with higher $\mathrm{pH}$ should be used. The numbers obtained are comparable to those obtained in studies in more acidic solutions, but the induced degradation is much less. With respect to fuel-cell applications, however, a low $\mathrm{pH}$ medium cannot be avoided. For application as a fuel-cell catalyst, polycrystalline Pd NPs are not the material of choice. Under ORR conditions, their activity is lower than that of bulk $\mathrm{Pd}$, and they show a significant dissolution rate at elevated potentials. Although the potentials applied in these studies are larger than under fuel-cell conditions, the standard potential of $\mathrm{Pd} / \mathrm{Pd}^{2+}$ is $0.915 \mathrm{~V}$ vs. SHE. Therefore, especially under conditions of low currents or even in idling, rapid degradation of the catalyst would be expected. For NPs with preferential exposure of certain crystal facets, a higher activity compared with the polycrystalline nanoparticles discussed in our work has been demonstrated in the literature, ${ }^{[7 a, 37]}$ however, stability can also be an issue in actual fuel-cell application in these cases.

The mechanism of catalyst loss on HOPG is not solely due to electrochemical dissolution, as discussed above. However, below a size of $8 \mathrm{~nm}$, detachment becomes the primary mechanism; dissolution takes place preferentially at the interface to the substrate. Here a modification of the support material might be beneficial for the overall stability of the catalyst, if this modification enables suppression of the interfacial dissolution reaction. An alternative pathway to suppress dissolution is alloying Pd with other elements.

With respect to enhancing our fundamental understanding, further studies need to be conducted to understand the deviations in the behaviour of small Pd particles with respect to the hydrogen reactions.

\section{Experimental Section}

\section{Chemical Compounds and Technical Equipment}

Metal deposition, electrochemical characterisation and reactivity measurements were performed in glass cells with a standard three-electrode arrangement using a Potentiostat-Galvanostat (Autolab PGSTAT 30). The solutions were prepared from $\mathrm{H}_{2} \mathrm{SO}_{4}(96 \%$, Merck, Suprapur), $\mathrm{Pd}\left(\mathrm{NO}_{3}\right)_{2}\left(\mathrm{Pd}\left(\mathrm{NO}_{3}\right)_{2}\right.$ solution, $16.27 \%$, Mateck), and $\mathrm{Na}_{2} \mathrm{SO}_{4}$ (99.5\%, Merck) with deionised water obtained from a Milli-Q (Millipore). Peroxymonosulfuric acid (Caro's acid) was prepared with $\mathrm{H}_{2} \mathrm{SO}_{4}$ (95-97\%, Merck, p.a.) and $\mathrm{H}_{2} \mathrm{O}_{2}(30 \%$, Merck, p.a.) at a volume ratio of 1:1. All glassware was cleaned in Caro's acid and rinsed extensively with deionised water. $\mathrm{Hg} / \mathrm{Hg}_{2} \mathrm{SO}_{4}$ reference electrodes (Schott, B3610) in $0.1 \mathrm{M} \mathrm{H}_{2} \mathrm{SO}_{4}\left(\mathrm{U}_{\text {ref }}=730 \mathrm{mV}\right.$ vs. $\mathrm{RHE}$ ) were used in all experiments. The potential values measured in $0.1 \mathrm{M} \mathrm{H}_{2} \mathrm{SO}_{4}$ electrolyte are referred to the reversible hydrogen electrode (RHE) unless specified otherwise. Palladium wires (99.95\%, Ögussa) were applied as counter electrodes and as working electrode in reference measurements. HOPG was purchased from Mikromasch (grade ZYD). The $\mathrm{pH}$ value of the electrolyte solutions was measured with a $\mathrm{pH}$ metre (Voltcraft, pH-100ATC). Surface images were obtained with a Veeco Multimode Electrochemical Scanning Tunneling Microscope/Atomic Force Microscope (ECSTM/AFM) system using atomic force microscopy in tapping mode (TM-AFM) under dry conditions. Phosphorus ( $n$ ) doped Si cantilevers (RTESPA, Bruker) were utilised. The AFM images were evaluated with WSXM 4.0 image analysis software (Nanotec Electronica S.L.). ${ }^{[44]}$

\section{Electrochemical Preparation and Characterisation of Pd NPs}

The HOPG surface was prepared before each experiment by cleaving the surface with an adhesive tape. The HOPG substrate was partially enclosed within Teflon tape, exposing a well-defined surface area of $0.126 \mathrm{~cm}^{2}$ to the electrolyte for the electrochemical measurements. The graphite surface was electrochemically oxidised by applying a $100 \mu$ s potential pulse at $5.73 \mathrm{~V}$ in $\mathrm{O}_{2}$ saturated $0.1 \mathrm{M} \mathrm{H}_{2} \mathrm{SO}_{4}$ solution to enhance the density of defects on the HOPG surface, because the metal particles tend to anchor at the step edge-sites or defect-sites of the HOPG surface. ${ }^{[45]}$

Pd deposition was performed from an aqueous solution of $0.5 \mathrm{~mm}$ $\mathrm{Pd}\left(\mathrm{NO}_{3}\right)_{2}$ in $0.1 \mathrm{M} \mathrm{H}_{2} \mathrm{SO}_{4}$. The solution was deaerated with argon gas and unstirred during deposition. The potentiostatic doublepulse technique was used for particle deposition. A short nucleation pulse of $10 \mathrm{~ms}$ at $U_{\mathrm{n}}=-70 \mathrm{mV}$ (at an overpotential of ca. $-960 \mathrm{mV}$ for $\mathrm{Pd}^{2+} / \mathrm{Pd} U_{0} \approx 890 \mathrm{mV}$ ), precedes a longer growth pulse at $U_{g}=220 \mathrm{mV}$. The duration of the growth pulse was varied from 1 to $200 \mathrm{~s}$ to control the particle size. The overpotential of the growth pulse was carefully selected so that the current during the growth pulse was approximately constant to achieve a narrow distribution of particle sizes. ${ }^{[20 d]}$ Before and after Pd deposition, the potential was kept at $915 \mathrm{mV}$ to avoid further deposition. After deposition, the Pd/HOPG sample was removed from the cell and rinsed with deionised water.

The $P d / H O P G$ samples were first characterised in Ar-purged $0.1 \mathrm{M}$ $\mathrm{H}_{2} \mathrm{SO}_{4}$. The active surface area of the Pd NPs was determined by the charge of $\mathrm{Pd}$ monoxide reduction from cyclic voltammetry $\left(424 \mu \mathrm{C} / \mathrm{cm}^{2}\right),{ }^{[46]}$ which is shown in Figure $1 \mathrm{e}$ as the integration over the shadow region. The upper and lower potentials were selected at $U_{\uparrow}=1.45 \mathrm{~V}$ and $U_{\downarrow}=0.3 \mathrm{~V}$ for the purposes of forming a complete $\mathrm{Pd}$ monoxide layer at the upper potential and avoiding the influence of hydrogen ad/absorption in the cathodic 
part. ${ }^{[46,47 a, b]}$ The adsorbed CO monolayer oxidation charge was also used in the same solution to determine the active area (shown as Figure $1 \mathrm{f}$ ). The working electrode was held in solution at $0.52 \mathrm{~V}$ with $\mathrm{CO}$ gas purging for $10 \mathrm{~min}$, therewith, Ar purging for $40 \mathrm{~min}$ to expel the dissolved $\mathrm{CO}$. The CV scanned over the same potential range as above. The charge transfer in CO stripping, which was integrated over the shadow region shown in Figure $1 \mathrm{f}$, was used $\left(330 \mu \mathrm{C} / \mathrm{cm}^{2}\right){ }^{[47 b]}$ The error bar in Figure $1 \mathrm{~d}$ was given by the difference of the two methods. As the bonding force of Pd NPs to HOPG is extremely weak, all activity measurements were carried out in a half-cell setup without any stirring. The activity measurements for HER were carried out in hydrogen saturated $0.1 \mathrm{M} \mathrm{H}_{2} \mathrm{SO}_{4}$ (with $\mathrm{H}_{2}$ gas purging for 10 min at open circuit). Linear-sweep voltammetry was measured in a potential range from 80 to $-220 \mathrm{mV}$ at a scan rate of $10 \mathrm{mV} \mathrm{s}^{-1}$. The electrocatalytic activity for ORR was measured in oxygen saturated $0.1 \mathrm{M} \mathrm{H}_{2} \mathrm{SO}_{4}$ (with $\mathrm{O}_{2}$ gas purging for $20 \mathrm{~min}$ at open circuit). Linear-sweep voltammetry was performed in a potential range from 930 to $280 \mathrm{mV}$ at a scan rate of $20 \mathrm{mVs}^{-1}$. Experiments using a RDE or RRDE setup could not be carried out due to the difficulty of machining single-crystalline HOPG with the accuracy required for mounting in a RDE holder.

The stability of $\mathrm{Pd} / \mathrm{HOPG}$ was investigated in $\mathrm{Ar}$ purged $0.1 \mathrm{M}$ $\mathrm{H}_{2} \mathrm{SO}_{4}(\mathrm{pH} 1), 0.1 \mathrm{M} \mathrm{Na}_{2} \mathrm{SO}_{4}+x \mathrm{mM} \mathrm{H}_{2} \mathrm{SO}_{4}(\mathrm{pH} 3)$ and $0.1 \mathrm{M} \mathrm{Na}_{2} \mathrm{SO}_{4}$ (pH 4.35) with potential cycles applied to the working electrode. Potential ranges were $0.3-1.45 \mathrm{~V}$ (vs. SHE) in $0.1 \mathrm{M} \mathrm{H}_{2} \mathrm{SO}_{4}, 0.182-$ $1.332 \mathrm{~V}$ (vs. SHE) in $0.1 \mathrm{M} \mathrm{Na}_{2} \mathrm{SO}_{4}+x \mathrm{mM} \mathrm{H}_{2} \mathrm{SO}_{4}$ and $0.102-1.252 \mathrm{~V}$ (vs. SHE) in $0.1 \mathrm{M} \mathrm{Na}_{2} \mathrm{SO}_{4}$. The lower and upper potentials were shifted based on the $\mathrm{pH}$ value of the electrolyte to compensate for the $\mathrm{pH}$ dependence of the PdO formation [cf. Eq. (3)]:

$\mathrm{Pd}+\mathrm{H}_{2} \mathrm{O} \rightleftharpoons \mathrm{PdO}+2 \mathrm{H}^{+}+2 \mathrm{e}^{-}$

The active surface area of Pd NPs in stability measurements was determined by the charge transferred during $\mathrm{Pd}$ monoxide reduction. TM-AFM was also used to determine the particle size and particle density.

\section{Acknowledgements}

The research leading to these results has received funding from the European Union's Seventh Framework Programme(FP7/20072013) for the Fuel Cells and Hydrogen Joint Technology Initiative under grant agreementn ${ }^{\circ}$ [303492], which is gratefully acknowledged. We acknowledge also financial support from Deutscher Akademischer Austauschdienst(DAAD) within the Vigoni bilateral program, and from the Carl von Linde foundation at Technische Universität München. W.J. thanks the China Scholarship Council for financial support. We would like to thank Dr. Hadwig Sternschulte and Simon Filser for helpful discussions.

Keywords: electrodeposition - heterogeneous catalysis hydrogen $\cdot$ nanoparticles $\cdot$ palladium

[1] Y. Sun, M. Delucchi, J. Ogden, Int. J. Hydrogen Energy 2011, 36, 11116 11127.

[2] a) A. Damjanovic, V. Brusić, Electrochim. Acta 1967, 12, 1171-1184; b) M Shao, J. Power Sources 2011, 196, 2433-2444.

[3] a) M. Haruta, Catal. Today 1997, 36, 153-166; b) M. Valden, X. Lai, D. W. Goodman, Science 1998, 281, 1647-1650; c) T. Brülle, W. Ju, P. Nieder- mayr, A. Denisenko, O. Paschos, O. Schneider, U. Stimming, Molecules 2011, 16, 10059-10077.

[4] O. Antoine, Y. Bultel, R. Durand, P. Ozil, Electrochim. Acta 1998, 43 $3681-3691$.

[5] M. S. El-Deab, T. Ohsaka, Electrochem. Commun. 2002, 4, 288-292.

[6] B. E. Hayden, Acc. Chem. Res. 2013, 46, 1858-1866.

[7] a) L. Xiao, L. Zhuang, Y. Liu, J. Lu, H. D. Abruna, J. Am. Chem. Soc. 2009, 131, 602-608; b) V. S. Bagotzky, Y. B. Vassiliev, I. I. Pyshnograeva, Electrochim. Acta 1971, 16, 2141-2167; c) S. Mukerjee, J. McBreen, J. Electroanal. Chem. 1998, 448, 163-171.

[8] a) N. Tateishi, K. Yahikozawa, K. Nishimura, M. Suzuki, Y. Iwanaga, M. Watanabe, E. Enami, Y. Matsuda, Y. Takasu, Electrochim. Acta 1991, 36, $1235-1240$; b) T.-h. Yang, S.-i. Pyun, Electrochim. Acta 1996, 41, $843-$ 848 ; c) R. C. Salvarezza, M. C. Montemayor, E. Fatas, A. J. Arvia, J. Electroanal. Chem. Interfacial Electrochem. 1991, 313, 291-301; d) M. Baldauf, D. M. Kolb, Electrochim. Acta 1993, 38, 2145-2153.

[9] N. M. Marković, C. A. Lucas, V. Climent, V. Stamenković, P. N. Ross, Surf. Sci. 2000, 465, $103-114$.

[10] M. H. Shao, T. Huang, P. Liu, J. Zhang, K. Sasaki, M. B. Vukmirovic, R. R. Adzic, Langmuir 2006, 22, 10409-10415.

[11] S. Pandelov, U. Stimming, Electrochim. Acta 2007, 52, 5548-5555.

[12] H. Wolfschmidt, R. Bussar, U. Stimming, J. Phys. Condens. Matter 2008 20, 374127

[13] B. Hammer, J. K. Nørskov in Advances in Catalysis (Eds.: H. K. Bruce C. Gates), Academic Press, Amsterdam, The Netherlands, 2000, pp. $71-$ 129.

[14] T. Bligaard, J. K. Nørskov, Electrochim. Acta 2007, 52, 5512-5516.

[15] L. A. Kibler, A. M. El-Aziz, D. M. Kolb, J. Mol. Catal. A 2003, 199, 57-63.

[16] a) L. A. Kibler, M. Kleinert, R. Randler, D. M. Kolb, Surf. Sci. 1999, 443, 1930; b) L. A. Kibler, M. Kleinert, D. M. Kolb, Surf. Sci. 2000, 461, 155-167; c) L. A. Kibler, M. Kleinert, V. Lazarescu, D. M. Kolb, Surf. Sci. 2002, 498, $175-185$.

[17] M. E. Björketun, G. S. Karlberg, J. Rossmeisl, I. Chorkendorff, H. Wolfschmidt, U. Stimming, J. K. Nørskov, Phys. Rev. B 2011, 84, 045407.

[18] P. Quaino, E. Santos, H. Wolfschmidt, M. A. Montero, U. Stimming, Catal. Today 2011, 177, 55-63.

[19] T. Brülle, U. Stimming, J. Electroanal. Chem. 2009, 636, 10-17.

[20] a) T. Brülle, A. Denisenko, H. Sternschulte, U. Stimming, Phys. Chem Chem. Phys. 2011, 13, 12883-12891; b) R. M. Penner, J. Phys. Chem. B 2002, 106, 3339-3353; c) M. Ueda, H. Dietz, A. Anders, H. Kneppe, A Meixner, W. Plieth, Electrochim. Acta 2002, 48, 377-386; d) H. Liu, F. Favier, K. Ng, M. P. Zach, R. M. Penner, Electrochim. Acta 2001, 47, $671-$ 677.

[21] M. Raşa, B. W. M. Kuipers, A. P. Philipse, J. Colloid Interface Sci. 2002, 250, $303-315$.

[22] J. V. Zoval, R. M. Stiger, P. R. Biernacki, R. M. Penner, The Journal of Physical Chemistry 1996, 100, 837-844.

[23] a) T. Maoka, M. Enyo, Electrochim. Acta 1981, 26, 607-614; b) T. Maoka, M. Enyo, Electrochim. Acta 1981, 26, 615-619.

[24] H. Duncan, A. Lasia, Electrochim. Acta 2008, 53, 6845-6850.

[25] A. Lasia, J. Electroanal. Chem. 2006, 593, 159-166.

[26] S. Schuldiner, G. W. Castellan, J. P. Hoare, J. Chem. Phys. 1958, 28, 16.

[27] W.-S. Zhang, Z.-L. Zhang, X.-W. Zhang, F. Wu, J. Electroanal. Chem. 1999 $474,123-129$.

[28] F. A. Lewis, Platinum Met. Rev. 1982, 26, 121-128.

[29] V. A. Vons, H. Leegwater, W. J. Legerstee, S. W. H. Eijt, A. Schmidt-Ott, Int. J. Hydrogen Energy 2010, 35, 5479-5489.

[30] a) N. M. Marković, P. N. Ross Jr, Surf. Sci. Rep. 2002, 45, 117-229; b) B. E. Conway, B. V. Tilak, Electrochim. Acta 2002, 47, $3571-3594$.

[31] D. Jose, B. R. Jagirdar, Int. J. Hydrogen Energy 2010, 35, 6804-6811.

[32] E. A. Owen, J. I. Jones, Proc. Phys. Soc. London 1937, 49, 587-602.

[33] a) L. A. Kibler, ChemPhysChem 2006, 7, 985-991; b) J. Greeley, J. K. Norskov, L. A. Kibler, A. M. El-Aziz, D. M. Kolb, ChemPhysChem 2006, 7, $1032-1035$.

[34] a) H. Erikson, A. Kasikov, C. Johans, K. Kontturi, K. Tammeveski, A. Sarapuu, J. Electroanal. Chem. 2011, 652, 1-7; b) H. Erikson, M. Liik, A. Sarapuu, J. Kozlova, V. Sammelselg, K. Tammeveski, Electrochim. Acta 2013, $88,513-518$; c) A. Sarapuu, A. Kasikov, N. Wong, C. A. Lucas, G. Sedghi, R. J. Nichols, K. Tammeveski, Electrochim. Acta 2010, 55, 6768-6774.

[35] A. Anastasopoulos, J. C. Davies, L. Hannah, B. E. Hayden, B. E. Lee, C. Mihano, C. Mormiche, L. Offin, ChemSusChem 2013, 6, 1973-1982. 
[36] S. Kondo, M. Nakamura, N. Maki, N. Hoshi, J. Phys. Chem. C 2009, 113, $12625-12628$.

[37] M. Shao, J. Odell, M. Humbert, T. Yu, Y. Xia, J. Phys. Chem. C 2013, 117, $4172-4180$

[38] M. Shao, A. Peles, K. Shoemaker, Nano Lett. 2011, 11, 3714-3719.

[39] Y. Cai, C. Ma, Y. Zhu, J. X. Wang, R. R. Adzic, Langmuir 2011, 27, $8540-$ 8547.

[40] B. R. Shrestha, A. Nishikata, T. Tsuru, Electrochim. Acta 2012, 70, 42-49.

[41] J. F. Llopis, J. M. Gamboa, L. Victori, Electrochim. Acta 1972, 17, 2225 2230.

[42] M. J. N. Pourbaix, J. V. Muylder, N. de Zoubov, Platinum Met. Rev. 1959, 3, 100-106.

[43] a) J. C. Meier, C. Galeano, I. Katsounaros, J. Witte, H. J. Bongard, A. A. Topalov, C. Baldizzone, S. Mezzavilla, F. Schuth, K. J. Mayrhofer, Beilstein J. Nanotechnol. 2014, 5, 44-67; b) J. C. Meier, I. Katsounaros, C. Galeano,
H. J. Bongard, A. A. Topalov, A. Kostka, A. Karschin, F. Schüth, K. J. J. Mayrhofer, Energy Environ. Sci. 2012, 5, 9319.

[44] I. Horcas, R. Fernandez, J. M. Gomez-Rodriguez, J. Colchero, J. GomezHerrero, A. M. Baro, Rev. Sci. Instrum. 2007, 78, 013705.

[45] M. Favaro, S. Agnoli, L. Perini, C. Durante, A. Gennaro, G. Granozzi, Phys. Chem. Chem. Phys. 2013, 15, 2923-2931.

[46] M. Grdeń, M. Łukaszewski, G. Jerkiewicz, A. Czerwiński, Electrochim. Acta 2008, 53, 7583-7598

[47] a) M. Hara, U. Linke, T. Wandlowski, Electrochim. Acta 2007, 52, 5733 5748; b) L.-I. Fang, Q. Tao, M.-f. Li, L.-w. Liao, D. Chen, Y.-x. Chen, Chin. J. Chem. Phys. 2010, 23, 543-548.

Received: November 9, 2014

Published online on January 14, 2015 